Research Paper:

\title{
A Prospective Study on the Role of Neurophysiological Studies in Predicting Functional Outcome After Lumbar Discectomy
}

\author{
Shanti Lal Sankhla ${ }^{1}$, Anshul Dahuja ${ }^{2^{*}}$, Rashmeet Kaur ${ }^{3}$, Jagdeep Singh ${ }^{2}$, Ankit Rai
}

1. Department of Orthopedics, Mahatama Gandhi Medical College, Jaipur, India

2. Department of Orthopedics, Guru Gobind Singh Medical College and Hospital, India

3. Department of Radiodiagnosis, Gobind Singh Medical College and Hospital, India

4. Departement of Orthopedics, All India Institute of Medical Sciences (AIIMS), Jodhpur, India

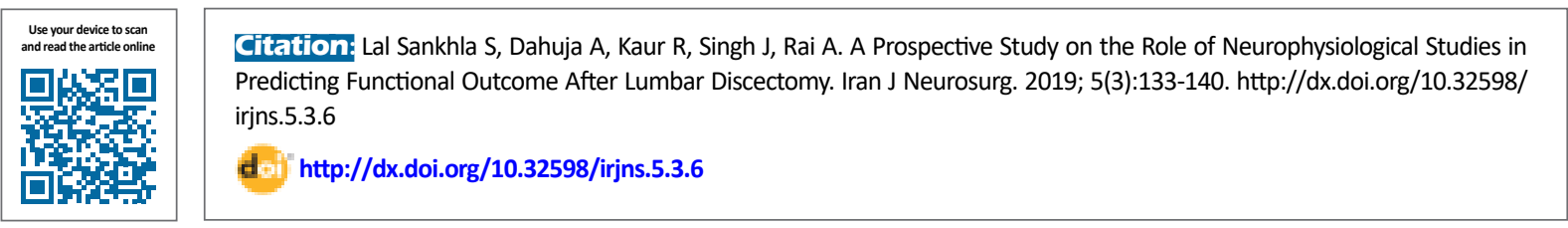

(a) $0 \Theta$

Article info:

Received: 13 Jan 2019

Accepted: 03 Jun 2019

Available Online: $01 \mathrm{Jul} 2019$

Keywords:

Low back pain, Visual analog scale, Intervertebral disc, Magnetic Resonance Imaging (MRI), Lumbar Vertebrae, Neuroimaging

\section{A B S T RACT}

Background and Aim: Lumbar intervertebral discs are complex anatomical structures essential for the mobility of intervertebral joints. There is general consensus for some indications for surgery, including acute or progressive neurological deficit(s), cauda equine syndrome, or refractory pain unresponsive to conservative treatments. However, controversy exists regarding the optimal management of cases with the disparity between radiological and clinical findings, which includes a great proportion of patients. This study examines whether neurophysiological studies can be used to identify subgroups with improved post-operative outcomes.

Methods and Materials/Patients: This prospective cohort study was conducted on 60 patients with clinical and imaging evidence in favor of Lumbar Disc Herniation (LDH). The pre-operative radiological assessment was the lateral X-rays in flexion and extension positions, and lumbar spine Magnetic Resonance Imaging (MRI). Pre-operative clinical assessment was done by the Oswestry Low Back Pain Disability Questionnaire and Visual Analog Scale (VAS). Neurophysiological studies were done at least one month after the onset of radiculopathy. Surgery was performed at the level suggested by neuroimaging. In all patients, we found an abnormal disc, which was removed along with any loose disc material. The patients were followed up for 1 year with intervals of 3 months for post-operative assessments.

Results: In the two study arms with abnormal or normal pre-operative electrodiagnostic studies, a significant decrease was observed in the percentages of visual analog scale reduction $173.69 \%$ and $95.59 \%$, respectively) and Oswestry disability score (65.3\% and $76.2 \%$, respectively) at the month 12 postoperative ( $P=0.993$ to 0.002 and $P=0.200$ to 0.037 , respectively).

Conclusion: Neurophysiological studies could be regarded as helpful adjuncts to distinguish a subgroup of patients with LDH, who may experience a favorable outcome after surgical intervention.

\section{* Corresponding Author:}

Anshul Dahuja, MS.

Address: Department of Orthopedics, Guru Gobind Singh Medical College and Hospital, India

Tel: +91 (730) 74203

E-mail:anshuldahuja@gmail.com 


\section{Highlights}

- Lumbar Disc Herniation (LDH), the leading cause of spinal surgery, is the most common diagnosis in degenerative abnormalities of the lumbar spine.

- There is a general consensus for some indications for surgery, including acute or progressive neurological deficit(s), cauda equine syndrome or refractory pain unresponsive to conservative treatments

- Neurophysiological and electrodiagnostic studies including Nerve Conduction Velocity (NCV) and Electromyography (EMG) assess the physiological function of nerve roots and therefore, confirm the extent of the damage at the anatomical site of the injury previously determined by Magnetic Resonance Imaging (MRI).

\section{Plain Language Summary}

Being the leading cause of spinal surgery, disc herniation is the most common diagnosis in degenerative abnormalities of the lumbar spine. Neuroimaging including plain x-ray films and MRI are the most important techniques to locate the site of the herniation. Neurophysiological studies (e.g. NCV and EMG) are supplementary techniques determining the extent of injury to the nerve roots caused by herniation. To prevent permanent nerve damage, surgical interventions is almost always need to be done to eliminate the pressure that is caused to the nerves. Although these surgical interventions are successful most of the time, thorough post-operative evaluations and comparison of the results with pre-operative results would benefit the process of employing the most suitable treatment strategy.

\section{Introduction}

isc herniation is the most common diag-

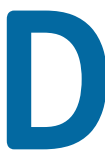
nosis in degenerative abnormalities of the lumbar spine and the leading cause of spinal surgery. Increased access to medical care, early requests for imaging tests, and the safety of surgical procedures have led to increased surgical treatment, which is usually self-limiting [1-4]. Therefore, a more closely related diagnostic method with high specificity of symptoms is needed to evaluate the subjects to determine appropriate treatment options [5, 6]. Neurophysiological Studies (NPS)/Electrodiagnostic Studies (EdX), including nerve conduction studies and electromyography, assess the physiological function of nerve roots or peripheral nerves.

EdX results have more consistency with clinical manifestations than Magnetic Resonance Imaging (MRI) results [7]. However, EdX cannot be used to diagnose underlying causes, such as tumors, herniated intervertebral discs, or spinal stenosis, which is favored on MRI. Despite MRI abnormalities, abnormal results in EdX can help to select the best treatment option [8]. Additionally, EdX can be used to differentiate many other neurodegenerative disorders, such as motor neuron disease, polyneuropathy or myopathy [9]. Therefore, $\mathrm{EdX}$ is considered a useful method for the evaluation of patients with lumbosacral radiculopathy combined with physical examination and radiological evaluations, including MRI [10].

Although evaluation of spinal surgery outcomes is traditionally based on fusion measures such as fusion status, recovery rate, or complication rate, the inclusion of a patient-specific assessment of outcomes has become the current practice [11-13]. Patient-reported outcomes (PROs) are usually measured with self-report questionnaires, as they are the main source of patient information [14]. The PRO Questionnaire, which is general or disease-specific, provides a quantitative assessment of pain, quality of life and functionality [15]. The VAS and Oswestry Low Back Pain Disability Questionnaire have been validated as useful measures for assessing pain and functional status, respectively.

The literature on the comparison of EdX with clinical outcomes is scant, and there is no clear diagnostic or research criteria for the diagnosis and selection of patients with Lumbar Disc Herniation (LDH) for surgery. It is important to give our patients a reasonable estimate of the disease.To our knowledge, this is the first prospective study with a larger cohort having a purpose to correlate neurophysiological studies with clinical outcomes. 


\section{Methods and Materials/Patients}

The current study was a prospective randomized controlled trial conducted on 60 patients who were diagnosed with $\mathrm{LDH}$ using clinical and neuroimaging methods, admitted to Guru Gobind Singh Medical College and Hospital, Faridkot India, from October 2017 to May 2018 with an average follow-up of one year. Our study included 60 patients with clinical and neuroimaging diagnosis of primary single or double level LDH with neurological deficits, low backache with neurogenic claudication with or without abnormal EDX studies, age $>18$ years, and failed conservative treatment. The exclusion criteria were having a history of spine surgery, inability to undergo neurophysiological studies, age $<18$ years, diabetes mellitus, polyneuropathy, inflammatory back pain, peripheral vascular disease, and rheumatic disease. A complete history was taken from all patients admitted to the department of orthopedics. They were examined thoroughly. Written informed consent was taken from the patients before participation in the study. The institutional ethical committee of Guru Gobind Singh medical college, Faridkot India approved the study (Code: BFUHS/2K17p/T11/-234).

The pre-operative radiological assessments were the lateral $\mathrm{X}$-rays in flexion and extension positions and lumbar spine MRI. Pre-operative clinical assessments included Oswestry Low Back Pain Disability Questionnaire and Visual Analog Scale (VAS). The Oswestry Low Back Pain Disability Questionnaire comprises 10 sections, each with a total score of 5 . The first statement was scored as 0 , and the last statement was scored as

5 . When all the 10 sections were completed by the patient, the score was calculated as percentage. For example, if the total score from 10 sections for 1 patient was 16 , the score of that patient would be $32 \%(16 / 50$ [maximal possible score] $\times 100$ ).

Neurophysiological parameters were assessed prior to surgery and with a mean of 42 days (3-13 weeks) after the onset of neurological deficit. This included Nerve Conduction Studies (NCS) and concentric needle
Electromyography (EMG) using a computerized EMG machine. The patient underwent surgery within 1 month of neurophysiologic testing. Laminectomy/ hemi-laminectomy with discectomy without fixation was performed at the level suggested by neuroimaging. In all patients, we found an abnormal disc, which was removed along with any loose disc material. The patients were followed up for 1 year with intervals of 3 months for post-operative assessments including Oswestry Low Back Pain Disability Questionnaire and VAS.

\section{Statistical analysis}

The data pertaining to demographic and other clinical variables were entered in the form of data matrix in Microsoft ${ }^{\circledR}$ Excel $^{\circledR}$ and analyzed using IBM $^{\circledR}$ SPSS $^{\circledR} \mathrm{V}$ 20.0.0. The normality and skewing of data were assessed through the Shapiro Wilk test and QQ plot. The difference of normally distributed continuous variables across two groups was explored using Independent Samples T-test and non-normal data using Mann Whitney $U$ test. The comparison of normally distributed continuous variables at more than two time points within a group was analyzed using one-way repeated measures analysis of variance and non-normal data using Friedman's Two-Way Analysis of Variance by Ranks. A p-value of less than 0.05 was considered as statistically signifi-cant for the purpose of this study.

\section{Results}

In our study, 60 patients were enrolled, out of which 22 were female $(36.7 \%)$ and 38 were male (63.3\%). The Mean \pm SD of the age of the patients was $42.37 \pm 14.42$ years, ranging from $19-70$. Detailed results are shown in Tables 1-4.

Nerve conduction studies were performed with surface electrodes and included motor conduction velocity, motor or distal motor latency, compound muscle action potential (CMAP) amplitude, and F-wave of the nerves served by the roots corresponding to the painful dermatome.

As showed in Table 1, our results showed that out

Table 1. Distribution of patients based on the result of pre-operative nerve conduction studies

\begin{tabular}{ccc}
\hline Pre-operative Nerve Conduction Status & Patient & \% \\
\hline Normal & 38 & 63.33 \\
Abnormal & 22 & 36.67 \\
Total & 60 & 100 \\
\hline & & NS
\end{tabular}


Table 2. Pre-operative Parameters of Electromyography

\begin{tabular}{lcc}
\hline Pre-operative Parameters & Status & No. (\%) \\
\hline \multirow{2}{*}{ Insertional activity } & Increased & $18(30)$ \\
& Normal & $42(70)$ \\
Spontaneous activity & Total & $60(100)$ \\
Fibrillation/ positive sharp wave + & Nil & $8(13.3)$ \\
Motor Unit Action Potential & Total & $10(16.7)$ \\
(MUAP) & Large amplitude / polyphasic & $42(70)$ \\
& Normal & $60(100)$ \\
\hline Recruitment & Total & $18(30)$ \\
& Reduced & $42(70)$ \\
& Normal & $60(100)$ \\
\hline & Total & $20(33.3)$ \\
\hline
\end{tabular}

of 60 patients, Nerve conduction studies were normal in 38 and abnormal in 22 patients.

The pre-operative parameters of EMG in which insertional activity was increased in 18 patients, spontaneously activity (fibrillation or positive sharp wave) was observed in $8+10=18$ patients, MUAP showed large amplitude/polyphasic in 18 and recruitment was decreased in 20 patients (Table 2 ).
As summarized in Table 3, there was a statistically significant difference in mean Oswestry Low Back Pain Disability Questionnaire Score between pre-operative and at month 12 post-operative time-points $(P=0.037)$ as shown in Figure 1. There was also a significant decrease in mean VAS score in groups of patients with both normal and abnormal neurophysiological studies in postoperative period as compared to the pre-operative results (Table 4). The VAS scores were also significantly

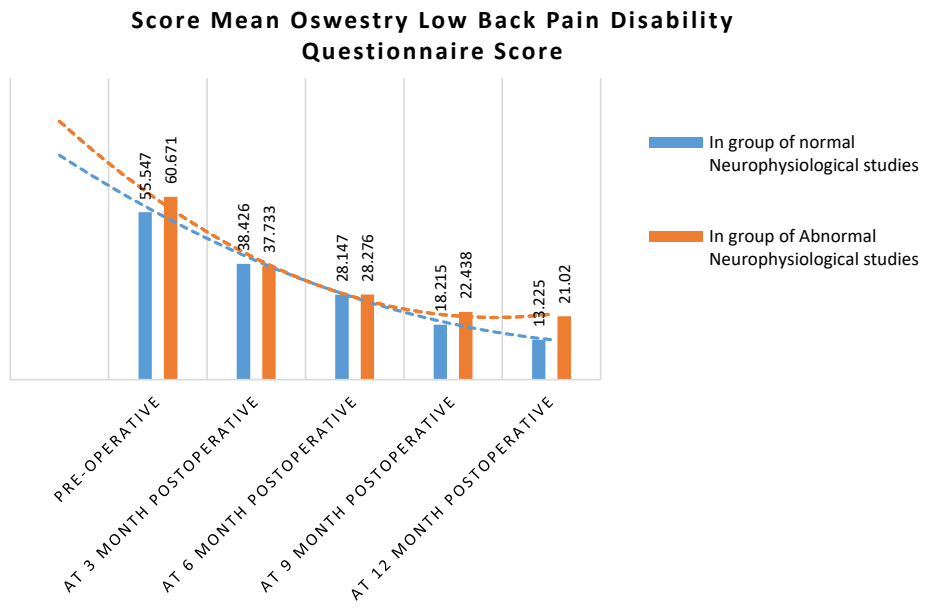

Figure 1. Bar graph showing the mean decrease in Oswestry Questionnaire 


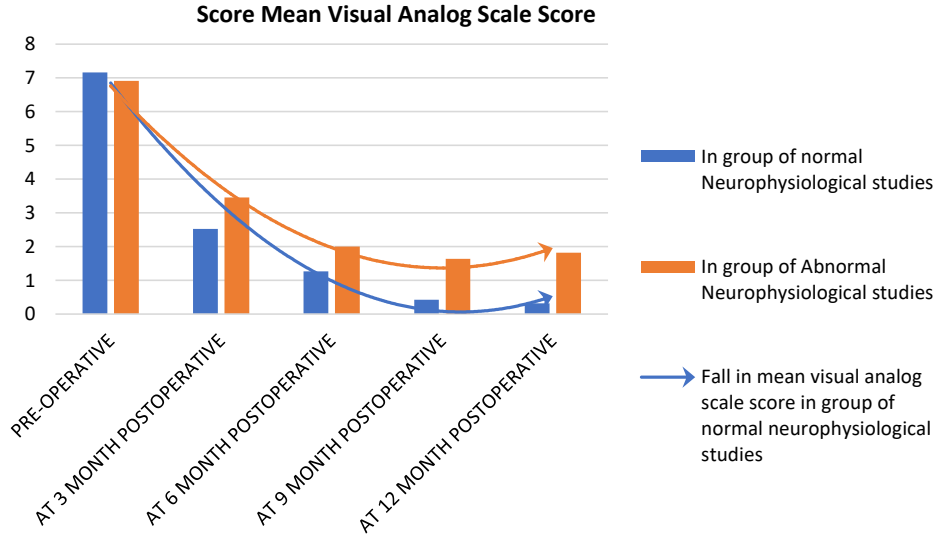

Figure 2. Bar graph showing the mean decrease in VAS score

different between pre-operative and months 9 and 12 post-operative time-points $(P=0.014$ and $P=0.002$, respectively) as shown in Figure 2, but the decrement was slightly reduced after 9 months post-operation in group with abnormal neurophysiological studies of 4 patients with complaints of reappearance of pain.

\section{Discussion}

In this study, we observed that pre-operative neurological deficit was present in $66.67 \%$ of the patients. Our results were in concordance with the results obtained by Falavigna et al., who reported the presence of neurological deficit in $66.1 \%$ of the patients with lumbar spine herniation [16]. It was observed that $6.66 \%$ of the patients had isolated motor defects, and $23.33 \%$ of the patients had mixed motor and sensory impairments. Traditionally, motor impairment in patients with LDH has been considered as a sign of severity by spinal surgeons.
In these patients, the incidence of motor impairment ranges from $15 \%-69 \%$ during the investigational or preoperative period. These studies did not specify different degrees of motor deficits, and only identified their prevalence in the studied populations and made comparisons between different pathologies such as LDH and central spinal stenosis. Despite the high incidence, motor deficits are not generally complained by patients as a factor affecting their general health during the preoperative period [17-21].

In the present study, the sole sensory deficit was present in $36.66 \%$ of the cases, while mixed motor and sensory and deficits were present in $23.33 \%$ of the cases. Therefore, the overall prevalence of sensory deficit was present in $60 \%$ of the cases. Our results were in concordance with the results obtained by Jönsson et al., who reported that sensory deficit was present in $62 \%$ of the cases [22].

Table 3. Comparison of mean Oswestry Low Back Pain Disability Questionnaire Scores in group of patients

\begin{tabular}{cccccc}
\hline $\begin{array}{c}\text { Mean Oswestry } \\
\text { Low Back Pain } \\
\text { Disability Question- } \\
\text { naire Score }\end{array}$ & $\begin{array}{c}\text { Normal } \\
\text { Neurophysi- } \\
\text { ological } \\
\text { studies }\end{array}$ & $\begin{array}{c}\text { Normal Neurophysi- } \\
\text { ological studies (de- } \\
\text { creased by \% compared } \\
\text { to pre-operative value) }\end{array}$ & $\begin{array}{c}\text { Abnormal Neu- } \\
\text { rophysiological } \\
\text { studies }\end{array}$ & $\begin{array}{c}\text { Abnormal Neuro- } \\
\text { physiological studies } \\
\text { (decreased by \% } \\
\text { compared to pre- } \\
\text { operative value) }\end{array}$ & $\begin{array}{c}\text { P (Mann } \\
\text { Whitney U- } \\
\text { test) }\end{array}$ \\
\hline Pre-operation & $55.547 \pm 10.19$ & - & $60.671 \pm 23.31$ & - & 0.200 \\
\hline $\begin{array}{c}\text { At month 3 post- } \\
\text { operation }\end{array}$ & $38.426 \pm 9.31$ & 30.83 & $37.733 \pm 12.75$ & 37.82 & 0.832 \\
$\begin{array}{c}\text { At month 6 post- } \\
\text { operation }\end{array}$ & $28.147 \pm 8.83$ & 49.34 & $28.276 \pm 12.48$ & 53.41 & 0.966 \\
$\begin{array}{c}\text { At month 9 post- } \\
\text { operation }\end{array}$ & $18.215 \pm 9.47$ & 67.22 & $22.438 \pm 9.97$ & 63.03 & 0.185 \\
\hline $\begin{array}{c}\text { At month 12 post- } \\
\text { operation }\end{array}$ & $13.225 \pm 9.21$ & 76.2 & $21.020 \pm 9.97$ & 65.36 & $0.037 *$ \\
\hline
\end{tabular}


Table 4. Comparison \& decrement of mean VAS Score in group of patients

\begin{tabular}{|c|c|c|c|c|c|}
\hline VAS Score & $\begin{array}{c}\text { Normal Neuro- } \\
\text { physiological } \\
\text { studies }\end{array}$ & $\begin{array}{l}\text { Normal Neuro- } \\
\text { physiological } \\
\text { studies (de- } \\
\text { creased by \% } \\
\text { compared to pre- } \\
\text { operative value) }\end{array}$ & $\begin{array}{l}\text { Abnormal Neurophysi- } \\
\text { ological studies }\end{array}$ & $\begin{array}{l}\text { Abnormal Neu- } \\
\text { rophysiological } \\
\text { studies (decreased } \\
\text { by } \% \text { compared } \\
\text { to pre-operative } \\
\text { value) }\end{array}$ & $\begin{array}{c}\text { P (Mann- } \\
\text { Whitney } \\
\text { U-test) }\end{array}$ \\
\hline Pre-operation & $7.158 \pm 2.34$ & - & $6.909 \pm 3.27$ & - & 0.933 \\
\hline $\begin{array}{l}\text { At month } 3 \text { post- } \\
\text { operation }\end{array}$ & $2.526 \pm 0.91$ & $64.72 \%$ & $3.455 \pm 1.29$ & $50.00 \%$ & 0.077 \\
\hline $\begin{array}{l}\text { At month } 6 \text { post- } \\
\text { operation }\end{array}$ & $1.263 \pm 0.99$ & $82.36 \%$ & $2.000 \pm 1.55$ & $71.06 \%$ & 0.232 \\
\hline $\begin{array}{l}\text { At month } 9 \text { post- } \\
\text { operation }\end{array}$ & $0.421 \pm 0.84$ & $94.12 \%$ & $1.636 \pm 1.21$ & $76.33 \%$ & $0.014^{*}$ \\
\hline $\begin{array}{l}\text { At month } 12 \\
\text { postoperation }\end{array}$ & $0.316 \pm 0.75$ & $95.59 \%$ & $1.818 \pm 1.08$ & $73.69 \%$ & $0.002^{*}$ \\
\hline
\end{tabular}

The overall prevalence of sensory deficit was 60 percent of the cases, which was higher than overall prevalence of motor deficit. Our results were in harmony with the results obtained by Mondelli et al., who reported the mean age of 47.7 years, range $18-64$ years, males: $55 \%$ in 108 consecutive patients. About $57 \%$ had sensory deficits and about $53 \%$ had motor deficits [23].

In our study, mean Oswestry Low Back Pain Disability Questionnaire Score in the group of patients with abnormal Neurophysiological studies at pre-operative time-point showed higher (60.7) than mean Oswestry Low Back Pain Disability Questionnaire Score in group of patients with normal Neurophysiological studies (55.5). Our results strengthened the results obtained by Lee et al. that reported similar findings in their study. Lee et al. described that patients with positive electrodiagnostic study EDX (+) had a significantly higher VAS for radiating pain and Oswestry Low Back Pain Disability Questionnaire Score (\%) than patients with negative electrodiagnostic study EdX (-), for both the total subject group and the herniated Intervertebral disc subgroup [24].

In the present study, we observed that the overall percentage decreased in the mean Oswestry Low Back Pain Disability Questionnaire Score $(76.20 \%$ at the month 12 postoperation) and VAS score (95.59\% at the month 12 postoperation) was significantly higher in patients with normal neurophysiological findings in comparison to the patients with abnormal neurophysiological findings. Our results favored the results obtained by Alrawi et al., who reported similar findings in patients undergoing cervical surgeries [25].
A study by Daniel et al. has concluded that a multidisciplinary approach is required to decrease the incidence of failed back syndrome (10-46\%) despite the increase in the advancement of technology [26]. The current study supports the role of electrodiagnostic studies to identify a subgroup of patients undergoing lumbar discectomy, which appear to have more favorable outcomes based on pre-operative test results.

Although our study has few limitations like heterogeneous group, lack of post-operative $\mathrm{EdX}$ studies, and short follow up period, it can be inferred from the results that patient group with pre-operative normal EdX studies has better post-operative clinical outcome than a pre-operative group with abnormal EdX studies. Therefore, electrodiagnostic studies may play an adjunct role in patients scheduled to undergo lumbar surgery for predicting the prognosis of the patients undergoing lumbar discectomy, but a larger cohort with longer follow up is required to establish our statement. The limitations of the study included heterogeneous group, short followup period, and lack of post-operative EdX studies.

\section{Conclusion}

Neurophysiological studies act as an important tool in predicting the outcome of lumbar spine surgery that can be helpful in better selection of patients and can reduce the incidence of failed back syndrome. 


\section{Ethical Considerations}

\section{Compliance with ethical guidelines}

This article is extracted from a thesis in Baba Farid University of Health Science, University in Faridkot, India. Written informed consent was taken from the patients before participation in the study. The institutional ethical committee of Guru Gobind Singh medical college, Faridkot India approved the study (Code: BFUHS/2K17p/T11/-234).

\section{Funding}

This research did not receive any specific grant from funding agencies in the public, commercial, or not-forprofit sectors.

\section{Authors' contributions}

Conceptualization and methodology: Shanti Lal Sankhla; Data collection: Shanti Lal Sankhla, Rashmeet Kaur, Jagdeep Singh, Anshul Dahuja; Drafting the article: Anshul Dahuja, Jagdeep Singh, Shanti Lal Sankhla, Ankit Rai; Critically revising the article, Reviewing the submitted version, and Approving the final version of the manuscript: All authors.

\section{Conflict of interest}

The authors declared no conflict of interest.

\section{Acknowledgments}

We would like to offer our special thanks to the Department of Social \& Preventive Medicine, Medicine and Physiology of Guru Gobind Singh medical college \& hospital, Faridkot, India.

\section{References}

[1] Colombier P, Clouet J, Hamel O, Lescaudron L, Guicheux J. The lumbar intervertebral disc: From embryonic development to degeneration. Joint Bone Spine. 2014; 81(2):125-9. [DOI:10.1016/j.jbspin.2013.07.012] [PMID]

[2] Amin RM, Andrade NS, Neuman BJ. Lumbar disc herniation. Current Reviews in Musculoskeletal Medicine. 2017; 10(4):50716. [DOI:10.1007/s12178-017-9441-4] [PMID] [PMCID]

[3] Kadow T, Sowa G, Vo N, Kang JD. Molecular basis of intervertebral disc degeneration and herniations: What are the important translational questions. Clinical Orthopaedics and Related Research. 2015; 473(6):1903-12. [DOI:10.1007/s11999014-3774-8] [PMID] [PMCID]
[4] Kepler CK, Ponnappan RK, Tannoury CA, Risbud MV, Anderson DG. The molecular basis of intervertebral disc degeneration. The Spine Journal. 2013; 13(3):318-30. [DOI:10.1016/j. spinee.2012.12.003] [PMID]

[5] Kalb S, Martirosyan NL, Kalani MYS, Broc GG, Theodore N. Genetics of the degenerated intervertebral disc World Neurosurgery. 2012; 77(3-4):491-501. [DOI:10.1016/j. wneu.2011.07.014] [PMID]

[6] Urban JPG, Roberts S. Degeneration of the intervertebral disc. Arthritis Research \& Therapy. 2003; 5(3):120. [DOI:10.1186/ ar629]

[7] Vialle LR, Vaille EN, Henao JES, Giraldo G. [Lumbar disc herniation (Portuguese)]. Revista Brasileira de Ortopedia. 2010; 45(1):17-22. [DOI:10.1590/S0102-36162010000100004] [PMID]

[8] Mixter WJ, Barr JS. Rupture of intervertebral disc with involvement of the spinal canal. The New England Journal of Medicine. 1934; 211:210-5. [DOI:10.1056/NEJM193408022110506]

[9] Martirosyan NL, Patel AA, Carotenuto A, Kalani MYS, Belykh E, Walker CT, et al. Genetic alterations in intervertebral disc disease. Frontiers in Surgery. 2016; 3:59. [DOI:10.3389/ fsurg.2016.00059] [PMID] [PMCID]

[10] Lama P, Le Maitre CL, Dolan P, Tarlton JF, Harding IJ, Adams MA. Do intervertebral discs degenerate before they herniate or after? The Bone \& Joint Journal. 2013; 95-B(8):1127-33. [DOI:10.1302/0301-620X.95B8.31660] [PMID]

[11] Blount KJ, Krompinger WJ, Maljanian R, Browner BD. Moving toward a standard for spinal fusion outcomes assessment. Journal of Spinal Disorders \& Techniques. 2002; 15(1):16-23. [DOI:10.1097/00024720-200202000-00003] [PMID]

[12] DeVine J, Norvell DC, Ecker E, Fourney DR, Vaccaro A, Wang J, et al. Evaluating the correlation and responsiveness of patient-reported pain with function and quality-oflife outcomes after spine surgery. Spine. 2011; 36:S69-S74 [DOI:10.1097/BRS.0b013e31822ef6de] [PMID]

[13] Glassman S, Gornet MF, Branch C, Polly Jr D, Peloza J, Schwender JD, et al. MOS short form 36 and oswestry disability index outcomes in lumbar fusion: A multicenter experience. The Spine Journal. 2006; 6(1):21-6. [DOI:10.1016/j. spinee.2005.09.004] [PMID]

[14] Hägg O, Fritzell P, Odén A, Nordwall A, The Swedish Lumbar Spine Study Group. Simplifying outcome measurement: Evaluation of instruments for measuring outcome after fusion surgery for chronic low back pain. Spine. 2002; 27(11):1213-22. [DOI:10.1097/00007632-200206010-00014] [PMID]

[15] McCormick JD, Werner BC, Shimer AL. Patient-reported outcome measures in spine surgery. Journal of the American Academy of Orthopaedic Surgeons. 2013; 21(2):99-107. [DOI:10.5435/JAAOS-21-02-99] [PMID]

[16] Falavigna A, Righesso O, Teles AR, Bossardi JB, da Silva PG. Pre-operative motor deficit in lumbar disc herniation and its influence on quality of life. Coluna/Columna. 2014; 13(4):282-6. [DOI:10.1590/S1808-18512014130400473]

[17] Righesso O, Falavigna A, Avanzi O. Correlation between persistent neurological impairment and clinical outcome after microdiscectomy for treatment of lumbar disc herniation. Neurosurgery. 2012; 70(2):390-6. [DOI:10.1227/ NEU.0b013e318231da4c] [PMID] 
[18] Grovle L, Haugen AJ, Keller A, Natvig B, Brox JI, Grotle $\mathrm{M}$. The bothersomeness of sciatica: Patients' self-report of paresthesia, weakness and leg pain. European Spine Journal. 2010; 19(2):263-9. [DOI:10.1007/s00586-009-1042-5] [PMID] [PMCID]

[19] Balague F, Nordin M, Sheikhzadeh A, Echegoyen AC, Skovron ML, Bech $\mathrm{H}$, et al. Recovery of impaired muscle function in severe sciatica. European Spine Journal. 2001; 10(3):242-9. [DOI:10.1007/s005860000226] [PMID] [PMCID]

[20] Junge A, Dvorak J, Ahrens S. Predictors of bad and good outcomes of lumbar disc surgery: A prospective clinical study with recommendations for screening to avoid bad out-comes. Spine. 1995; 20(4):460-8. [DOI:10.1097/00007632-19950200100009] [PMID]

[21] Patrick DL, Deyo RA, Atlas SJ, Singer DE, Chapin A, Keller RB. Assessing health-related quality of life in patients with sciatica. Spine. 1995; 20(17):1899-908. [DOI:10.1097/00007632199509000-00011] [PMID]

[22] Jonsson B, Stromqvist B. Symptoms and signs in degeneration of the lumbar spine. A prospective, consecutive study of 300 operated patients. The Journal of Bone and Joint Surgery. British Volume. 1993; 75-B(3):381-5. [DOI:10.1302/0301620X.75B3.8496204]

[23] Spangfort EV. The lumbar disc herniation: A computeraided analysis of 2,504 operations. Acta Orthopaedica Scandinavica. 1972; 43(Suppl 142):1-99. [DOI:10.3109/ort.1972.43. suppl-142.01] [PMID]

[24] Lee JH, Lee SH. Physical examination, magnetic resonance image, and electrodiagnostic study in patients with lumbosacral disc herniation or spinal stenosis. Journal of Rehabilitation Medicine. 2012; 44(10):845-50. [DOI:10.2340/165019771034] [PMID]

[25] Alrawi MF, Khalil NM, Mitchell P, Hughes SP. The value of neurophysiological and imaging studies in predicting outcome in the surgical treatment of cervical radiculopathy. European Spine Journal. 2007; 16(4):495-500. [DOI:10.1007/ s00586-006-0189-6] [PMID] [PMCID]

[26] Daniell JR, Osti OL. Failed back surgery syndrome: A review article. Asian Spine Journal. 2018; 12(2):372-9. [DOI:10.4184/asj.2018.12.2.372] [PMID] [PMCID] 